\title{
Sodium Current Density Correlates with Expression of Specific Alternatively Spliced Sodium Channel mRNAs in Single Neurons
}

\author{
Diane K. O'Dowd, ${ }^{1,2}$ Joey R. Gee, ${ }^{1,2}$ and Martin A. Smith \\ Departments of ${ }^{1}$ Anatomy and Neurobiology and ${ }^{2}$ Developmental and Cell Biology, University of California Irvine, \\ Irvine, California 92717
}

\begin{abstract}
Elements within the first cytoplasmic loop of voltage-gated sodium channels have been implicated in regulating channel function. We have examined the role of alternative splicing within the first cytoplasmic loop of the Drosophila sodium channel gene para in regulating sodium current expression, using single-cell RT-PCR. In addition to a previously described exon (a), we identified a second exon in this region, designated exon $i$. Alternative splicing of exons $a$ and $i$ results in the expression of four para transcripts that are present individually or in combination within single neurons. Analysis of sodium current density and the pattern of para mRNA expression suggested that the presence of exon a was necessary though not sufficient for expression of sodium currents in cultured embryonic neurons. A similar pattern of alternative splicing of para mRNA was also evident in RNA isolated from whole embryos. Combined with our observation that the patterns of alternative splicing of para mRNA change during development, these findings suggest that neuronal sodium current expression in vivo, is also modulated by alternative splicing.
\end{abstract}

[Key words: alternative splicing, sodium channels, Drosophila, gene regulation, single-cell $R T-P C R$, para]

Voltage-gated sodium channels play a key role in electrical excitability of cells in vertebrate and invertebrate nervous systems. While all sodium channels share a number of common features, specific sodium channel subtypes are characterized by distinct pharmacological sensitivities, gating properties, and patterns of localization (Weiss and Horn, 1986; Gordon et al., 1987; Jones, 1987; Huguenard et al., 1988; Beckh et al., 1989; Westenbroek et al., 1989; Campbell, 1992). In mammals, the array of functionally distinct sodium channels arises, at least in part, through transcriptional regulation of multiple genes that encode unique sodium channel $\alpha$-subunits (Trimmer et al., 1989; Joho et al., 1990; Kallen et al., 1990; White et al., 1991). Other studies have demonstrated that protein kinase-dependent phosphorylation events can also regulate channel function (Numann et al., 1991; West et al., 1991; Gershon et al., 1992; Li et al., 1992, 1993; Smith and Goldin, 1992; Qu et al., 1994). Thus, both transcrip-

\footnotetext{
Received Sept. 29. 1994: revised Dec. 7. 1994: accepted Dec. 19. 1994

We thank Drs. A. Agmon. K. G. Bina, L. P. Henderson, J. Massengill, and R. A. Mauc for their helpful comments on earlier versions of the manuscript. This work was supported by NIH Grants NS 27501 and NS 30109 to D.K.O. and NS 3321.3 to M.A.S., as well as a Committee of 1000 Young Investigator Award to M.A.S.

Correspondence should be addressed to Diane K. O'Dowd, Department of Anatomy and Neurohiology. University of California Irvine, Irvine, CA 92717. Copyright 1995 Society for Neuroscience $0270-6474 / 95 / 154005-08 \$ 05.00 / 0$
}

tional and posttranslational mechanisms are likely to play an important role in regulating expression of sodium currents in excitable cells (for reviews, see Catterall, 1992; Kallen et al., 1993; Mandel, 1993).

The possibility that alternative splicing might represent an additional mechanism contributing to sodium channel diversity was initially suggested following isolation of two cDNAs (IIN and IIA) encoded by the type II sodium channel gene in rat (Auld et al., 1988; Sarao et al., 1991; Yarowsky et al., 1991). More recently, it has been shown that both rat brain type I and type III sodium channel genes are also subject to alternative splicing (Schaller et al., 1992; Gustafson et al., 1993). The optional inclusion of small exons located within the large cytoplasmic loop between homologous domains I and II suggested a possible role for alternative splicing in regulating the potential for sodium channel phosphorylation (Schaller et al., 1992). However, the functional consequences of alternative splicing in this region remain to be determined.

Although only a single gene, para, has been shown to encode functional sodium channels in Drosophila (Loughney et al., 1989; O’Dowd et al., 1989), electrophysiological analyses demonstrate a varied pattern of sodium channel expression in Drosophila neurons (O'Dowd and Aldrich, 1988; Saito and $\mathrm{Wu}$, 1991; O'Dowd, 1995). These findings suggest that in Drosophila, posttranscriptional mechanisms are likely to be important in generating sodium channel diversity. Consistent with this possibility, structural analysis of the para gene indicates the presence of a number of microexons that give rise to multiple alternatively spliced para mRNAs (Loughney et al., 1989; Thackeray and Ganetzky, 1994). However, neither the tissue specificity nor function of the proteins encoded by these para mRNAs is known.

Here we begin to examine the potential role of alternative splicing of the para gene in regulating sodium channel function. In this study we focus our attention on exon usage in the first intracellular domain of the sodium channel for two reasons. First, in rat sodium channels, function can be modulated by phosphorylation of cAMP-dependent protein kinase (PKA) target sites in the first intracellular loop (Gershon et al., 1992; Li et al., 1992; Smith and Goldin, 1992). Second, of the two consensus PKA sites identified in the first cytoplasmic loop of the para sodium channel, one is contained within the alternatively spliced exon a (Loughney et al., 1989). The results of our study suggest that alternative splicing of exons containing PKA sites represents an important mechanism whereby sodium channel expression is regulated. 


\section{Materials and Methods}

Cell culture. Cultures were prepared from mid-gastrula stage embryos. Embryos were collected and dechorionated by immersion for 5-7 min in a $50 \%$ solution of bleach. Sharp micropipettes were used to puncture the vitelline membrane and to remove cells that were dispersed on uncoated glass coverslips. Cultures were grown in Drosophila Defined Medium I (DDM1; O'Dowd, 1995), consisting of HAM's F-12/DMEM (high glucose) supplemented with sodium bicarbonate, $1 \mathrm{mg} / \mathrm{ml}$; HEPES, $20 \mathrm{~mm}$; putrescine, $100 \mu \mathrm{M}$; hydrocortisone, $50 \mathrm{nM}$; selenium, 30 $\mathrm{nM}$; progesterone, $20 \mathrm{ng} / \mathrm{ml}$; insulin, $50 \mu \mathrm{g} / \mathrm{ml}$; and transferrin, $100 \mu \mathrm{g} /$ $\mathrm{ml}$. Cultures were maintained in a $5 \% \mathrm{CO}_{2}$ environment at $22-26^{\circ} \mathrm{C}$. Neurons chosen for study were generally isolated or in pairs. The majority of cells were studied at $2 \mathrm{~d}$ in culture; some cells were examined at 1 or $4 \mathrm{~d}$.

Electrophysiolugical recording. Coverslips with cultured cells were transferred to a recording chamber mounted on a Nikon TMS inverted microscope and visualized with Hoffman optics at a magnification of $600 \times$. Electrophysiological recordings were obtained using the wholecell configuration of the patch-clamp technique (Hamill et al., 1981). Recording pipettes were not polished and had open pipette resistances of 2-5 $\mathrm{M} \Omega$. The majority of the experiments were conducted with internal solution containing (mM) potassium gluconate (120), $\mathrm{KCl}(20)$, HEPES (10), EGTA (1.1), $\mathrm{CaCl}_{2}(0.1)$, and $\mathrm{MgCl}_{2}(2)$, pH 7.2. In some experiments a second internal solution was used containing (mM) $\mathrm{KCl}$ (70), KF (70), HEPES (10), EGTA (1.1), $\mathrm{CaCl}_{2}(0.1)$, and $\mathrm{MgCl}_{2}(2)$, pH 7.2. No difference was noted in the results obtained with these two different internal solutions. The external solution contained (mM) $\mathrm{NaCl}$ (140), $\mathrm{MgCl}_{2}$ (4), $\mathrm{HEPES}$ (5), $\mathrm{CaCl}_{2}$ (1), and $\mathrm{KCl}$ (3), $\mathrm{pH}$ 7.2. Following formation of a high-resistance seal, the capacitance associated with the electrode and patch was subtracted electronically prior to rupture of the patch. Upon breaking into the cell, the whole-cell capacitance was determined by integrating the area under the capacitative transient in a current record obtained by averaging the current responses elicited by 10 depolarizing voltage steps from -70 to $-60 \mathrm{mV}$. Data were collected and analyzed using a List EPC-7 patch-clamp amplifier, a Dell 386 computer, and pCLAMP software (Axon Instruments, version 5.5.1). All recordings were performed at room temperature.

Harvesting of cellular RNA and PCR amplification. Single-cell RTPCR analysis was performed essentially as previously described (Smith and O'Dowd, 1994). At the end of the electrophysiological recording, the contents of the cell were aspirated into the pipette tip and rapidly expelled into $7.5 \mu \mathrm{l}$ of ice-cold first-strand cDNA synthesis mixture (0.67 mM dNTPs (Pharmacia), $6.7 \mu \mathrm{M}$ random hexanucleotide primers (Pharmacia), $10 \mathrm{U}$ of RNasin (Promega) in $1.3 \times$ reverse transcriptase buffer (GIBCO-Bethesda Research Labs) and subsequently stored on ice for up to $4 \mathrm{hr}$. First-strand CDNA was synthesized by addition of $100 \mathrm{U}$ of Moloney murine leukemia virus reverse transcriptase (GIBCO-Bethesda Research Labs) to bring the mixture to a final volume of $10 \mu \mathrm{l}$, followed by incubation at $37^{\circ} \mathrm{C}$ for $1 \mathrm{hr}$. Five or $10 \mu \mathrm{l}$ of the resulting cDNA was subject to a single round of amplification in a 50 $\mu l$ reaction for 35 cycles using primer pairs DP1/DP2 (annealing temperature $57^{\circ} \mathrm{C}$ ) or DP3/DP4 (annealing temperature $54^{\circ} \mathrm{C}$ ) that flank the region of alternative splicing of exon a (Loughney et al., 1989). PCR products were labeled by inclusion of approximately $2 \times 10^{5} \mathrm{cpm}$ of either DP1 or DP3 in each reaction, labeled with ${ }^{32} \mathrm{P}$ using T4 kinase (Sambrook et al., 1989). Twenty microliters of the amplified reaction mixture were fractionated by electrophoresis on an $8 \%$ polyacrylamide gel and the relative levels of each PCR product determined by analysis on a phosphorimager using the IMAGEQUANT software package (Molecular Dynamics). The identity of each PCR product was verified by direct sequencing using the fmol DNA Sequencing System (Promega) according to the manufacturer's instructions.

To rule out the possibility that differences in the pattern of para expression between cells might result from contamination between reagents or individual PCR reactions, the following controls were performed in each experiment. First, an aliquot of the external recording medium was aspirated into the pipette and subsequently treated as a sham cell. In each experiment, one such medium control was taken every four to nine cells. In addition, all experiments included a control in which an equivalent amount of water was substituted in place of cell cytoplasm for the first-strand cDNA synthesis. Experiments were accepted for analysis only if all control lanes were negative. Based on this criterion, data from 2 of 22 experiments were excluded from the study.

Total RNA isolation and PCR amplification. Total RNA was isolated by the single-step method of Chomczynski and Sacchi (1987) from pools of 18-20 hr embryos, first instar larvae (48 hr), pupae (P13-P15), and adult fly heads. cDNA templates were synthesized in a $10 \mu \mathrm{l}$ reaction by reverse transcription of total RNA (10-50 ng/ $\mu$ l) using Moloney's murine leukemia virus reverse transcriptase $(10 \mathrm{U} / \mu \mathrm{l}$; GIBCOBethesda Research Labs) with random hexanucleotide primers ( $5 \mathrm{pmol} /$ $\mu \mathrm{l}$; Pharmacia-I.KB) and dNTPs ( $0.5 \mathrm{~mm}$; Pharmacia-LKB) incubated for $1 \mathrm{hr}$ at $37^{\circ} \mathrm{C}$. Subsequently, $10 \mu \mathrm{l}$ of cDNA was amplified by PCR in a $50 \mu \mathrm{l}$ reaction for 35 cycles using primer pairs DP1/DP2 or DP3/ DP4 as described above for the single cells. The relative levels of each PCR product was determined by gel electrophoresis and phosphorimager analysis.

Primers used in this study were as follows: DP1, GCTATTTGTTGGCGGCGAGA; DP2, ATTCTCTTCGGACATCGGGG; DP3, ATGTCCATTCGGAGCGTCGA; DP4, CTGGGCATCCTGATATGTTGACA.

\section{Results}

\section{Expression of alternatively spliced para isoforms in single} neurons

We used RT-PCR to characterize the pattern of alternative splicing in the region of exon a in RNA isolated from single embryonic Drosophila neurons maintained in cell culture. Isolated cells with large somata and neuronal morphology (Fig. 1A) were selected for analysis. Following formation of a high-resistance seal on the cell soma, the contents of the cell was aspirated into the patch pipette and transferred to a microfuge tube where mRNA was reverse transcribed and cDNA subsequently amplified by PCR using primers flanking exon a. Analysis of the resulting amplification products by gel electrophoresis followed by autoradiography (Fig. $1 B$ ) indicated that para transcripts including the 21 amino acid exon a, as well as transcripts excluding exon a, were expressed in many cells. However, we also observed additional bands from some cells (Fig. $1 B$ ), suggesting the presence of a previously uncharacterized alternatively spliced exon within the region amplified.

To confirm the identity of the PCR products and examine the exon organization within this region of the para gene, each of the PCR products was isolated and sequenced directly (Fig. 1C). Consistent with the results of the gel electrophoresis, sequence analysis showed that in addition to exon a, a second alternatively spliced exon was also located within this region. In line with the previously established convention (Loughney et al., 1989) we have named this exon i. Exon i encodes 24 amino acids and is located immediately $5^{\prime}$ to exon a. Thus alternative splicing resulting in inclusion or exclusion of exons a and i gives rise to four para isoforms referred to as $\mathrm{i}^{+} \mathrm{a}^{+}, \mathrm{i}^{+} \mathrm{a}^{-}, \mathrm{i}^{-} \mathrm{a}^{+}$, and $\mathrm{i}^{-} \mathrm{a}^{-}$(Fig. $1 C)$.

The results of our initial studies indicated that PCR products representing four alternatively spliced para mRNAs could be resolved at the single-cell level. PCR products were obtained from 131 of $258(51 \%)$ neurons examined in 20 separate experiments. Since we were unable to control for variables such as harvesting of cell cytoplasm, neurons from which a PCR product was not amplified were not analyzed further. Estimates of the expression frequency of each isoform indicate that $\mathrm{i}^{+} \mathrm{a}^{-}$ and $\mathrm{i}^{+} \mathrm{a}^{+}$are the most frequently expressed transcripts, each present in approximately $85 \%$ of the neurons sampled (Fig. $2 A$ ). In comparison, the percentage of neurons expressing $\mathrm{i}^{-} \mathrm{a}^{+}$and $\mathrm{i}^{-} \mathrm{a}^{-}$ are four- to fivefold lower. Consistent with this observation, the majority of cells expressed at least two para mRNAs, while approximately $20 \%$ and $15 \%$ of the cells expressed one or three para transcripts, respectively. To characterize the para mRNA expression profile in single cells in more detail we determined the relative abundance of each isoform as a percentage of the 
A
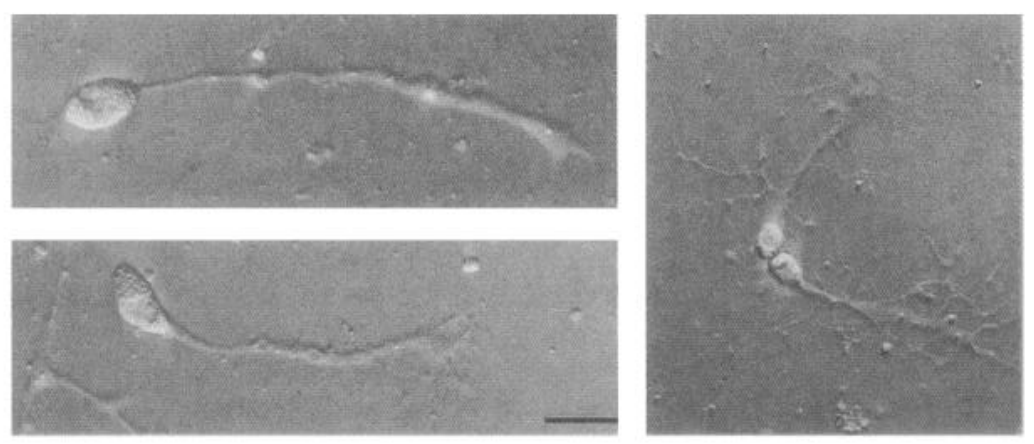

B

$\begin{array}{llllllllll} & 2 & \mathrm{mc} & 3 & \mathrm{mc} & 4 & 5 & 6 & 7 & 8 \\ \mathrm{mc} w c\end{array}$

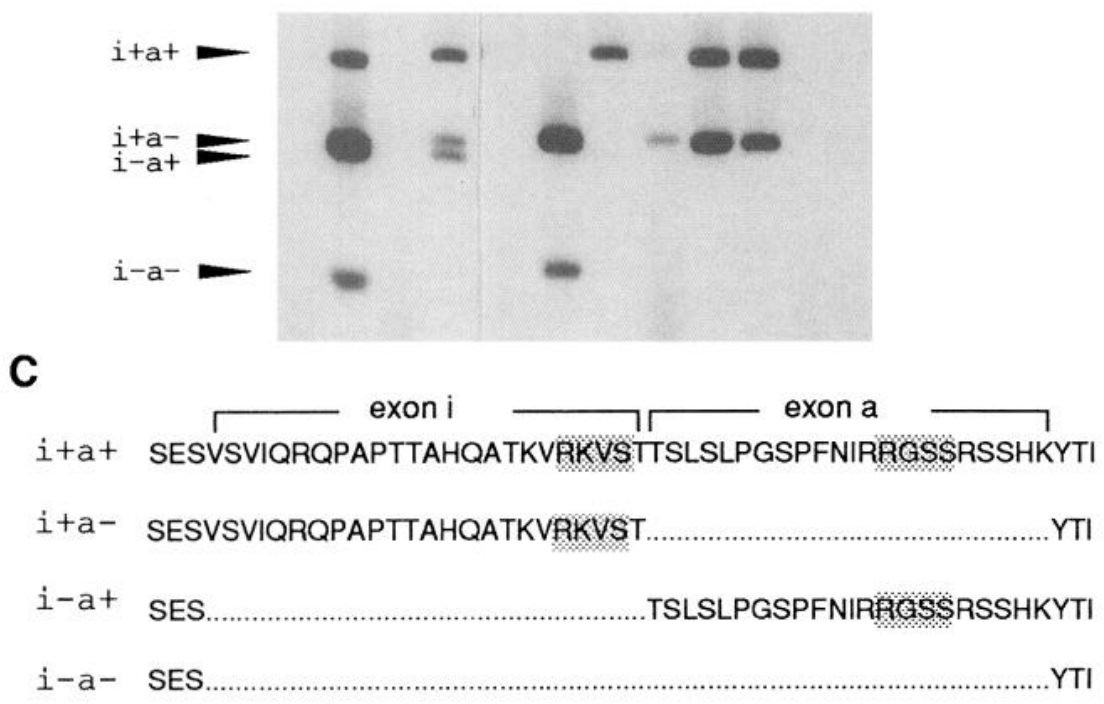

Figure 1. Para mRNA profiles of individual embryonic neurons. $A$, Examples of isolated neurons with large cell bodies and neuritic processes after $2 \mathrm{~d}$ in primary cultures prepared from mid-gastrula stage Drosophila embryos grown in a chemically defined medium. Scale bar, $20 \mu \mathrm{m}$. B, Composite autoradiogram from a single experiment showing four distinct para transcripts amplified from RNA harvested from single cells. Whereas lane $l$ represents a cell in which no product was amplified, one or more para transcripts were amplified from each of the other seven cells (lanes 2-8). The media controls $(m c)$, in which medium was aspirated into the tip of a whole-cell pipette in place of a cell, and the water control $(w c)$, in which water was used in place of contents of a cell in the first-strand cDNA synthesis and processed in parallel with the experimental lanes, are all negative. The largest product, para $\mathrm{i}^{+} \mathrm{a}^{+}$, results from inclusion of two exons a and i, encoding 21 and 24 amino acids, respectively. The larger of the two intermediate products, $\mathrm{i}^{+} \mathrm{a}^{-}$, results from inclusion of exon $\mathrm{i}$ and exclusion of exon a. The smaller of the intermediate products, $\mathrm{i}^{-} \mathrm{a}^{+}$, excludes exon $\mathrm{i}$ and includes exon a. The smallest product, $\mathrm{i}^{-} \mathrm{a}^{-}$, lacks both exons. $C$, The sequence of each of the four alternatively spliced transcripts shows the locations of exons $i$ and $a$. Consensus PKA sites are shaded. total para mRNA expressed in a given neuron. These values were subsequently averaged over all cells for which a para PCR product was amplified to obtain the mean relative abundance for each isoform. The results of this analysis showed that $\mathrm{i}^{+} \mathrm{a}^{+}$and $\mathrm{i}^{+} \mathrm{a}^{-}$were not only the most frequently expressed but were also the most abundant isoforms, present at approximately equal levels in single neurons. In comparison, the relative abundance's of $\mathrm{i}^{-} \mathrm{a}^{+}$and $\mathrm{i}^{-} \mathrm{a}^{-}$were four- to fivefold lower.

We were interested in determining whether the differences in para expression profile in individual neurons represented heterogeneity between cells, or rather, a simple Poisson distribution reflecting statistical sampling of limiting template RNA for the different isoforms present in a single cell. Two experiments were designed to address this question. In the first, cytoplasm obtained from either two or four cells was pooled and cDNA synthesized from each pool was split into equal aliquots (representing either one or two cell equivalents) for separate PCR amplification. In six of six reactions, the pattern of expression of the high-abundance para mRNAs $\left(\mathrm{i}^{+} \mathrm{a}^{+}, \mathrm{i}^{+} \mathrm{a}^{-}\right)$was both qualitatively and quantitatively similar in the two independent amplifications (Fig. 3 , Exp. 1). These findings suggest that at the level of the single cell, the technique affords a reasonable estimate of expression of the high-abundance isoforms. However, in one of the cases (Fig. 3, panel 3), one of the two low-abundance isoforms $\left(i^{-} a^{-}\right)$ appeared in reaction $\mathrm{A}$, while the other low-abundance isoform $\left(\mathrm{i}^{-} \mathrm{a}^{+}\right)$appeared in reaction $\mathrm{B}$. This suggests that at least some of the observed heterogeneity we see may arise from a statistical sampling error, particularly in the cases of the low-abundance messages. This question was further examined in a second splitting experiment in which cDNA synthesized from single cells was divided into equal aliquots, amplified in separate PCR reactions and the products of sister reactions compared (Fig. 3, Exp. 2). In 11 of 19 neurons, both qualitatively and quantitatively similar para mRNA profiles were obtained in both amplifications (Fig. 3, panels 4, 5), even in cells containing lowabundance isoforms (panel 5). Moreover, clear differences in para mRNA profile were still evident between cells. These findings demonstrate that some of the heterogeneity in para mRNA profiles between cells reflects actual differences in the relative abundance of different mRNAs in these cells.

\section{Sodium current density and para mRNA profiles}

Drosophila neurons maintained in cell culture exhibit heterogeneity in sodium current expression both in terms of current density (O'Dowd and Aldrich, 1988) and kinetics (Saito and Wu, 1991; O'Dowd, 1995). We were intrigued by the possibility that differences in the properties of the whole-cell sodium current might correspond with expression of specific alternatively spliced para mRNAs. To examine this question, 63 cells in which both stable whole-cell recordings and PCR products were obtained were subject to further analysis. The results of a typical experiment are shown in Figure 4. Sodium currents were recorded from both cells 1 and 2, which expressed $\mathrm{i}^{+} \mathrm{a}^{+}$alone, or $\mathrm{i}^{+} \mathrm{a}^{+}$in conjunction with other para transcripts, respectively. In 
A

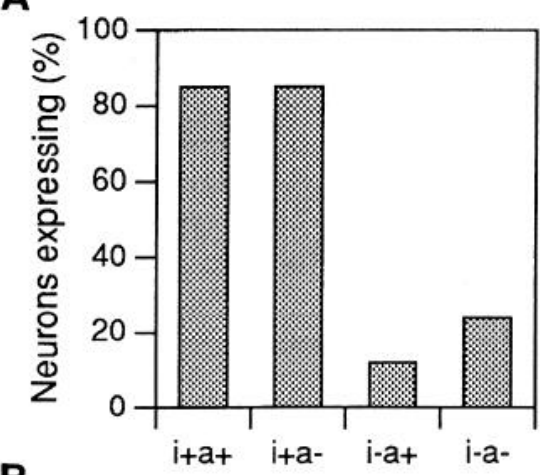

B

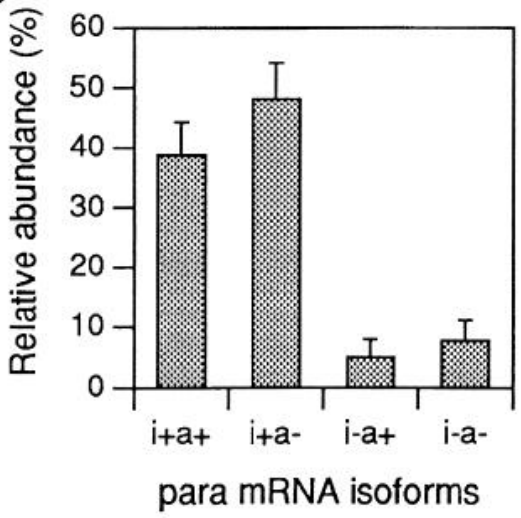

Figure 2. Frequency of appearance and relative abundance of specific para isoforms in single cells. A, The fraction of cells expressing each para isoform. $B$. The relative abundance of each para mRNA in individual neurons was determined using a phosphorimager. Bar charts summarize data from 34 neurons in which PCR products were obtained. SEMs are indicated.

contrast, no sodium current was detected in cell 3 , which contained only the $\mathrm{i}^{+} \mathrm{a}^{-}$isoform. These results suggested that the $\mathrm{i}^{+} \mathrm{a}^{+}$isoform may be necessary for sodium current expression. To examine this question quantitatively we compared the mean sodium current density recorded from neurons in which the levels of $\mathrm{i}^{+} \mathrm{a}^{+}$mRNA were below detection, with that of neurons expressing $\mathrm{i}^{+} \mathrm{a}^{+}$transcripts (Fig. 5). Of the 63 neurons examined, the average sodium current density of the 15 cells lacking $\mathrm{i}^{+} \mathrm{a}^{+}$ was very low $(1.7 \pm 0.9 \mathrm{pA} / \mathrm{pF})$. However, 14 of 15 of these cells contained significant levels $(>45 \%)$ of the $\mathrm{i}^{+} \mathrm{a}^{-}$transcript. In contrast, the average sodium current density from the 48 neurons expressing at least some of the $\mathrm{i}^{+} \mathrm{a}^{+}$isoform, was significantly larger, $13.2 \pm 2.9 \mathrm{pA} / \mathrm{pF}$ (mean $\pm \mathrm{SEM})$.

To determine whether one or both exons were necessary for sodium current expression, we wanted to examine currents in cells whose para mRNA profile lacked transcripts containing either exon a or i. Although there were no cells that lacked both possible transcripts containing exon i, our data set contained four neurons that lacked any exon a containing mRNAs. No detectable sodium currents were evident in any of the neurons lacking exon a. These findings suggest that exon a or exon a together with exon i, but not exon i alone, are necessary for sodium current expression.

While the $\mathrm{i}^{+} \mathrm{a}^{+}$transcripts may be necessary for expression of sodium currents, there was not a simple linear correlation between the relative abundance of this transcript and sodium current density. For example, we identified neurons that expressed little or no sodium current, even when the $i^{+} a^{+}$was clearly the

\section{Experiment 1 1-2 cell equivalents/lane}

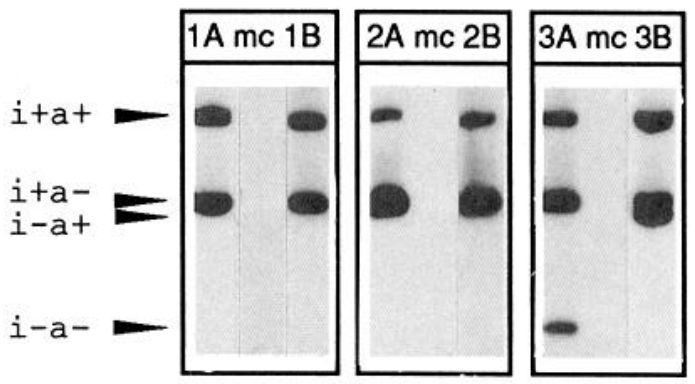

Experiment 20.5 cell equivalents/lane

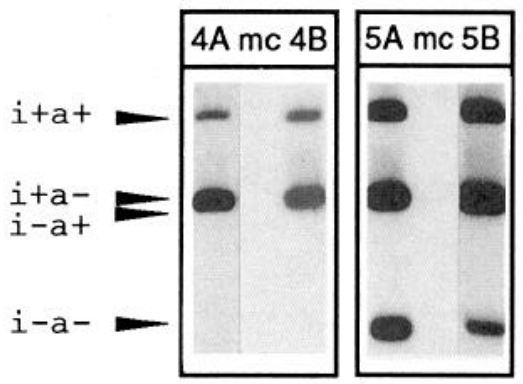

Figure 3. Variation in para mRNA profiles between single cells. Experiment 1 , Composite autoradiogram from an experiment in which the cDNA synthesized from the pooled cytoplasm from either two or four cells was divided into two aliquots (representing one or two cell equivalents) and amplified in separate PCR reactions $(A$ and $B)$. Panels $I$ and 2 represent reactions in which the same isoforms with a similar relative abundance profile were amplified in both reactions $A$ and $B$. Panel 3 is a case where the two high-abundance isoforms $\left(\mathrm{i}^{+} \mathrm{a}^{+}\right.$and $\left.\mathrm{i}^{+} \mathrm{a}^{-}\right)$appear qualitatively similar in both reactions $A$ and $B$; however, the $\mathrm{i}^{-} \mathrm{a}^{-}$isoform appears only in amplification $A$, while the $\mathrm{i}^{-} \mathrm{a}^{+}$isoform appears only in amplification B. Experiment 2, Composite autoradiogram from an experiment in which cDNA from single cells were split into two aliquots (representing 0.5 cell equivalent) and amplified in separate PCR reactions ( $A$ and $B$ ). Panels 4 and 5 represent cells in which qualitatively and quantitatively similar para expression profiles were obtained in both reactions $A$ and $B$. This demonstrates that there is real variation between individual cells as the reproducible profiles of cells 4 and 5 , are different from each other. The media controls $(m c)$ processed in parallel with the experimental lanes in both Experiments 1 and 2 , are negative.

most abundant isoform expressed. Conversely, there were cells that contained relatively low amounts of $\mathrm{i}^{+} \mathrm{a}^{+}$transcripts (20$30 \%$ of the total) that had large sodium current amplitudes (data not shown). These findings suggest that while the presence of transcripts containing exon a may be necessary for the expression of high levels of sodium current, they are not sufficient.

\section{Pattern of splicing in whole embryos and developmental regulation of exon usage}

To determine whether the pattern of exon a and i usage observed in vitro might also be present in vivo, RNA isolated from 18$20 \mathrm{hr}$ embryos, first instar larvae, P13-15 pupae, and adult heads was reverse transcribed and amplified by PCR. All four para transcripts observed in single neurons in culture were represented in RNA from each developmental stage examined (Fig. $6 A$ ). The para mRNA profile obtained from whole embryos was similar to the average profile obtained from single neurons, consistent with the conclusion that the population of cells sampled during the single-cell analysis was representative of the popu- 


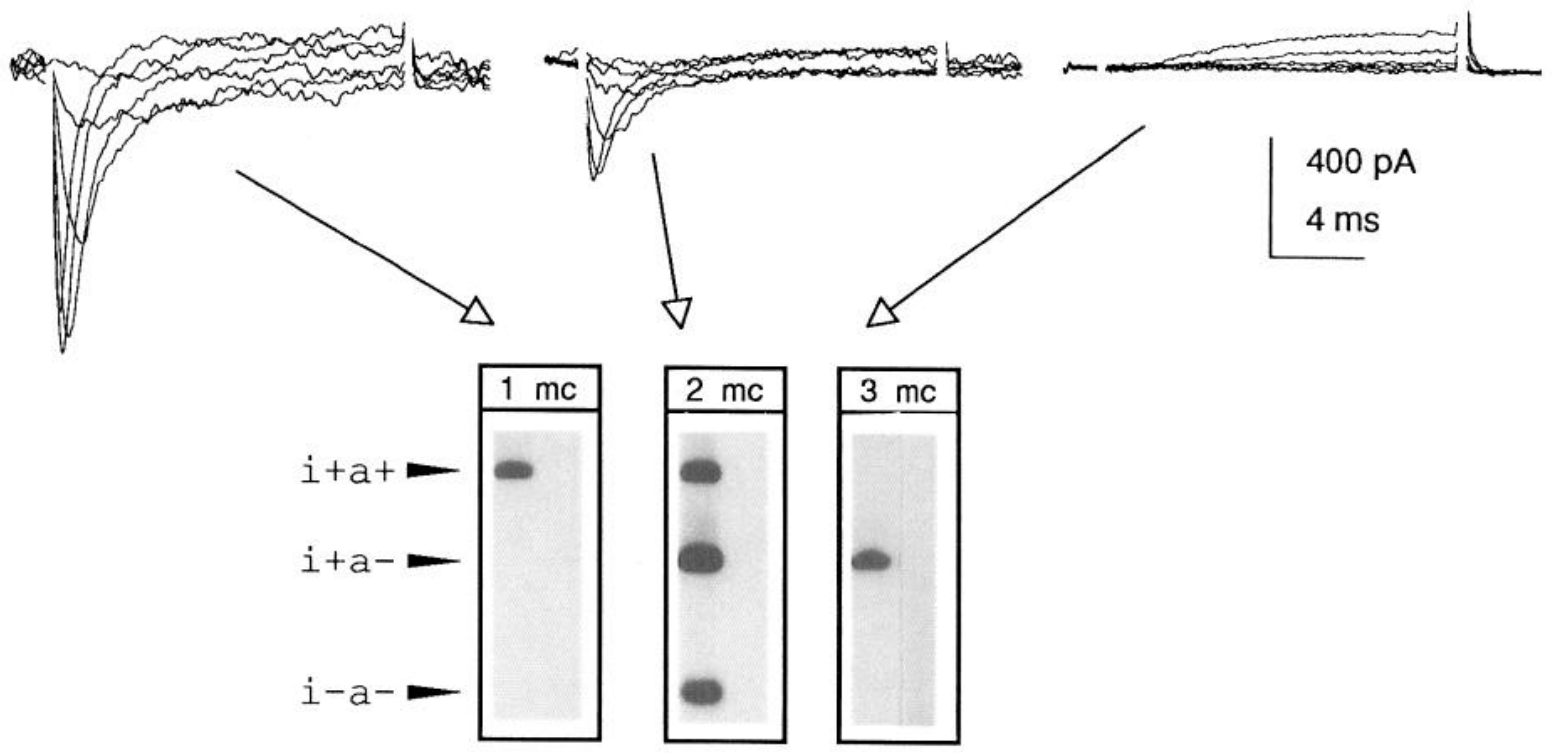

Figure 4. Variation in sodium current amplitude and para mRNA expression profiles between individual neurons: whole-cell currents recorded from three embryonic neurons after $2 \mathrm{~d}$ in culture in response to a series of depolarizing voltage steps presented at $10 \mathrm{mV}$ increments between -40 and +10 , from a holding potential of $-80 \mathrm{mV}$. Autoradiograms of the PCR products amplified from these three cells are shown below. Note that both cells $I$ and 2 contain the $\mathrm{i}^{+} \mathrm{a}^{+}$transcript and express sodium currents. No sodium currents were recorded from cell 3 in which only the $\mathrm{i}^{+} \mathrm{a}^{-}$isoform was amplified. Similar, small amplitude outward potassium currents were observed in all three cells. The three amplifications run as sham cells $(m c)$ were blank as expected.

lation present in the whole embryo (Fig. 6B). Quantitative comparison reveals that, with the exception of larvae, the most abundant transcript in each of the developmental stages is $\mathrm{i}^{+} \mathrm{a}^{-}$, comprising between $4 \%$ and $72 \%$ of the total para mRNA (Fig. $6 \mathrm{C}$ ). The other major transcript, $\mathrm{i}^{+} \mathrm{a}^{+}$, represents approximately $35-$ $40 \%$ of total para mRNA in the embryo and larval stages with lower levels of expression evident in the adult head. Whereas peak levels of $\mathrm{i}^{-} \mathrm{a}^{+}$expression were seen in pupal RNA, ex-

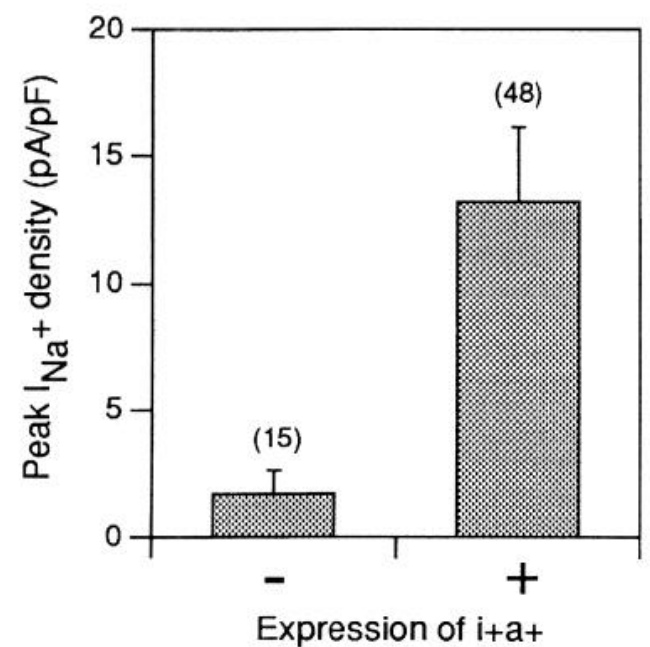

Figure 5. $\mathrm{i}^{+} \mathrm{a}^{+}$mRNA is correlated with high sodium current density: bar chart showing the mean sodium current density of cells lacking (-) or containing $(+)$ the $\mathrm{i}^{+} \mathrm{a}^{+}$para mRNA. The difference between the two groups is significant at the $p<0.05$ level (two-tailed, unpaired Student's $t$ test). Error bars indicate SEM. Number of cells in each group is indicated. pression of $\mathrm{i}^{-} \mathrm{a}^{-}$, the other low-abundance transcript, was maximal in embryonic and larval RNA.

\section{Discussion}

Alternative splicing contributes to the structural diversity of sodium channels in species as evolutionarily distant as rat and Drosophila, yet little is known concerning the role of alternative splicing in modulating sodium channel function. We have measured sodium current density and the pattern of expression of alternatively spliced para mRNAs in single embryonic Drosophila neurons. The results of these studies suggest that alternative splicing events occurring within the first cytoplasmic loop of the sodium channel $\alpha$-subunit, regulate a neuron's potential to express a sodium current. The observation that RNA isolated from embryos, pupae, larvae, and adult fly heads, exhibit a characteristic pattern of alternative splicing of para mRNA expression in the same region further suggests that regulation of sodium channel function by alternative splicing is likely to be important in normal development.

\section{Functional consequences of alternative splicing of the para} sodium channel gene

Alternative splicing events at multiple sites throughout the primary para transcript have been predicted to give rise to as many as 48 different para mRNAs (Thackeray and Ganetzky, 1994). Our analysis revealed the existence of an additional alternatively spliced exon, exon i, located immediately upstream of exon a. Optional inclusion of exons a and i gives rise to four transcripts, all of which are expressed at the level of the single cell. Marked variability was apparent in the levels of sodium current expressed by individual embryonic neurons. Thus, for alternative splicing of the para gene in this region to be important in reg- 
A

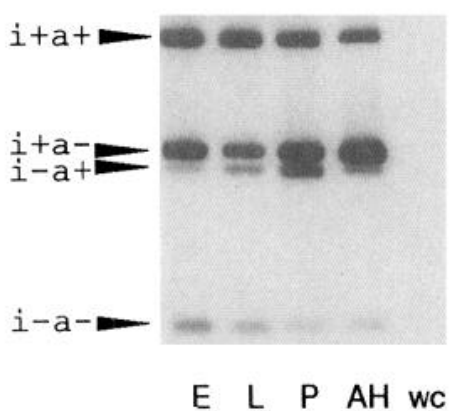

B

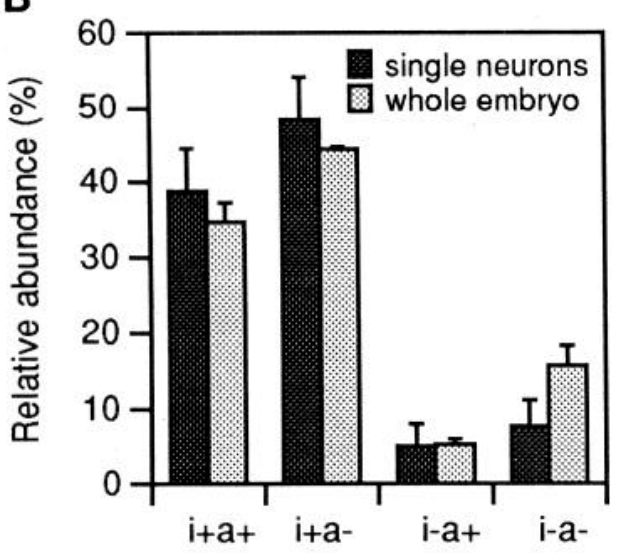

C

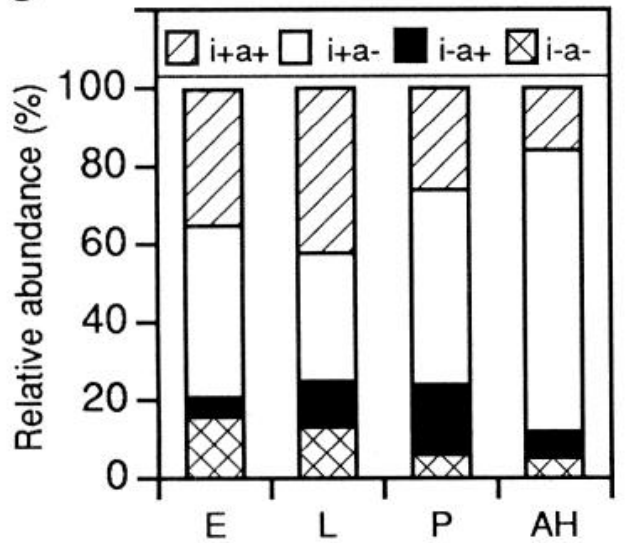

Figure 6. Alternative splicing of para in vivo. A, Autoradiogram of a typical experiment illustrating that all four para transcripts arising from the optional inclusion of exons $\mathrm{i}$ and a are expressed in the whole animal: first-strand cDNA synthesized from RNA isolated from 18-20 hr embryos $(E)$, first instar larvae $(L)$, P13-P15 pupae $(P)$, and adult head $(A H)$, was amplified by PCR. ' $B$, The levels of expression of each transcript were quantified on a phosphorimager and expressed as a fraction of total para product. The bar chart compares the mean relative abundance of each of the isoforms obtained from three separate experiments for the whole embryo RNA with that calculated from 34 single embryonic neurons. As can be seen relative abundance profiles are similar in the two conditions. $C$, Bar diagram showing the mean relative abundance of each isoform obtained from three separate experiments at each of the developmental stages indicated. A distinct para mRNA expression profile is seen at each developmental stage examined. ulating channel function, one would predict that differences in the expression pattern of different para transcripts between individual cells should also exist. We did in fact observe considerable variation in the mRNA profiles of individual cells both in terms of the different isoforms expressed and their relative abundance. We considered the possibility that this may simply reflect stochastic sampling errors based on the availability of limiting template in a single cell. The results of our splitting experiments however, suggest that in a significant number of instances, differences between the levels of expression in single cells are real. Variation in the para expression profile and sodium current expression observed in individual cells is consistent with the possibility that sodium channel function may be regulated by alternative splicing.

Analysis of sodium currents in single cells suggested that sequences associated with either exon a and/or exon i, are necessary for sodium channel expression. Several lines of evidence suggest that inclusion of exon a is critical for expression of a sodium current. First, in neurons lacking detectable levels of $\mathrm{i}^{+} \mathrm{a}^{+}$, the mean sodium current density was very low. All of these cells contained significant levels of the other high-abundance transcript, $\mathrm{i}^{+} \mathrm{a}^{-}$. Second, in four cells that lacked any mRNAs containing exon a, no sodium current was detected. Thus, whereas exon $\mathrm{i}$ alone is not sufficient for expression of high levels of sodium current, amino acid sequences associated with exon a, either alone, or in conjunction with exon $\mathrm{i}$ appear to play an important role in regulating sodium current density. A second interpretation of these data is that splicing of exon a is linked to inclusion (or exclusion) of an exon(s) elsewhere in the protein that itself affects sodium current expression directly. Recent analysis has demonstrated that alternative splicing of certain pairs or groups of exons within the para gene are not independent of one another (Thackeray and Ganetzky, 1994). While we cannot rule out this alternate explanation, the conclusion that sodium current density is modulated by alternative splicing of the para gene still stands.

What are the functions of para transcripts excluding exon a? While we do not have any data that bare directly on this issue, it is possible that they encode (1) proteins that fail to assemble or assemble and make nonfunctional channels, (2) functional channels that are localized in the membrane at sites electrically distant from the recording electrode (e.g., on the distal ends of processes) and therefore not detected, or (3) channels with gating properties that are not well resolved by the techniques used in the present study. Previous studies have demonstrated that alternatively spliced variants of other channel types, such as the Shaker potassium channel, encode proteins with distinct kinetic properties when expressed in Xenopus oocytes (Iverson et al., 1988; Timpe et al., 1988a,b; Zagotta et al., 1989). In the present analysis, we do not know whether changes in sodium current density reflect changes in the number of sodium channels and/ or their biophysical properties. To examine the gating and kinetic properties of sodium currents that might reveal additional correlation's with specific para isoforms, we are currently conducting experiments to examine sodium currents in isolation.

\section{Potential mechanisms underlying physiological function of transcripts containing both exons $i$ and $a$}

Our data suggest that the presence of $\mathrm{i}^{+} \mathrm{a}^{+}$transcripts are necessary for the expression of high sodium current density. However, the finding that some cells expressing high levels of $\mathrm{i}^{+} \mathrm{a}^{+}$ transcripts have no detectable sodium currents while conversely 
others with only moderate levels of $i^{+} \mathbf{a}^{+}$transcripts express large sodium currents, suggests a second mechanism influences sodium current expression that is nevertheless dependent on the presence of these exons. Previous studies have demonstrated that sodium channel function can be modulated by phosphorylation of specific PKA sites in the first cytoplasmic linking region of mammalian sodium channels (Gershon et al., 1992; Li et al., 1992; Smith and Goldin, 1992). Interestingly in the para sodium channel, both exons $\mathrm{i}$ and a contain a predicted PKA site. Thus, the phosphorylation potential of the large cytoplasmic domain in para is regulated by alternative splicing. One plausible explanation therefore is that variation in sodium current density in the presence of high levels of $\mathrm{i}^{+} \mathrm{a}^{+}$is associated with different basal levels of phosphorylation of exons a and/or $i$. A recent study has demonstrated that regulation of sodium currents by PKA also requires concurrent activation of sodium channels by PKC at a distinct site ( $\mathrm{Li}$ et al., 1993). Therefore, it is equally possible that regulation of sites distinct from those in the first intracellular loop, either through alternative splicing or state of phosphorylation, could influence the current flowing through the para sodium channels expressed by these different isoforms. To address these issues it will be necessary to determine whether it is possible to modulate the current through para sodium channels by cAMP-dependent protein kinase and/or protein kinase $\mathrm{C}$ and to determine whether this can be correlated with presence or absence of specific exons.

\section{Alternative splicing in vivo}

The observation that transcripts lacking exon $\mathrm{i}$ are expressed in RNA isolated from whole animals, demonstrates that the potential array of para transcripts expressed in vivo, as we see in vitro, is more complex than previously believed (Loughney et al., 1989; Thackeray and Ganetzky, 1994). The finding that the average single-cell profile of cultured embryonic neurons is similar to that seen in whole embryos, suggests that a similar level of heterogeneity is present among cells developing in vivo. A unique pattern of para mRNA expression was apparent in RNA obtained from animals at different developmental stages. For instance, the relative abundance of $\mathrm{i}^{-} \mathrm{a}^{+}$increases threefold between the embryonic and pupal stages. Levels of para mRNA containing exon a also decline twofold in RNA obtained from embryos versus adult head. A recent and broader analysis of exon usage in para reports a similar decrease in abundance of exon a containing mRNAs between embryos and adults (Thackeray and Ganetzky, 1994). The observation that alternative splicing of exons $\mathrm{i}$ and $\mathrm{a}$ is regulated during development suggests that alternative splicing in this region also plays a role in regulating sodium current expression in vivo.

\section{References}

Auld VJ, Goldin AL, Krafte DS, Marshall J, Dunn JM, Catterall WA, Lester HA, Davidson N, Dunn RJ (1988) A rat brain $\mathrm{Na}^{+}$channel $\alpha$-subunit with novel gating properties. Neuron 1:449-461.

Beckh S, Noda M, Lubbert H, Numa S (1989) Differential regulation of three sodium channel messenger RNAs in the rat central nervous system during development. EMBO J 8:3611-3616.

Campbell D (1992) Large and small vertebrate sensory neurons express different $\mathrm{Na}$ and $\mathrm{K}$ channel subtypes. Proc Natl Acad Sci USA 89: 9569-9573.

Catterall WA (1992) Cellular and molecular biology of voltage-gated sodium channels. Physiol Rev 72:S15-S48.

Chomcrynski P, Sacchi N (1987) Single-step method of RNA isolation by acid guanidinium thiocyanate-phenol-chloroform extraction. Anal Biochem 162:156-159.
Gershon E, Weigl L, Lotan I, Schreibmayer W, Dascal N (1992) Protein kinase A reduces voltage-dependent $\mathrm{Na}^{+}$current in Xenopus oocytes. J Neurosci 12:3743-3752.

Gordon D, Merrick D, Auld V, Dunn R, Goldin AL, Davidson N, Catterall WA (1987) Tissue-specific expression of the RI and RII sodium channel subtypes. Proc Natl Acad Sci USA 84:8682-8686.

Gustafson TA, Clevinger EC, O'Neill TJ, Yarowsky PJ, Krueger BK (1993) Mutually exclusive exon splicing of type III brain sodium channel $\alpha$ subunit RNA generates developmentally regulated isoforms in rat brain. $\mathbf{J}$ Biol Chem 268:18648-18653.

Hamill O, Marty A, Neher E, Sakmann B, Sigworth FJ (1981) Improved patch-clamp techniques for high-resolution current recording from cells and cell-free membrane patches. Pfluegers Arch 391:85100 .

Huguenard JR, Hamill OP, Prince DA (1988) Developmental changes in sodium conductances in rat neocortical neurons: appearance of a slowly inactivating component. J Neurophysiol 59:778-794.

Iverson LE, Tanouye MA, Lester HA, Davidson N, Rudy B (1988) Atype potassium channels expressed from Shaker locus cDNA. Proc Natl Acad Sci USA 85:5723-5727.

Joho RH, Moorman JR, VanDonegen AM, Kirsch GE, Silberberg H, Schuster G, Brown AM (1990) Toxin and kinetic profile of rat brain type III sodium channels expressed in Xenopus oocytes. Mol Brain Res 7:105-113.

Jones S (1987) Sodium currents in dissociated bull-frog sympathetic neurons. J Physiol (Lond) 389:605-627.

Kallen RG, Sheng Z-H, Yang J, Chen L, Rogart RB, Barchi RL (1990) Primary structure and expression of a sodium channel characteristic of denervated and immature rat skeletal muscle. Neuron 4:233-242.

Kallen RG, Cohen SA, Barchi RL (1993) Structure, function, and expression of voltage-dependent sodium channels. Mol Neurobiol $7: 383-428$.

Li M, West JW, Lai Y, Scheuer T, Catterall WA (1992) Functional modulation of brain sodium channels by cAMP-dependent phosphorylation. Neuron 8:1151-1159.

Li M, West JW, Numann R, Murphy BJ, Scheuer T, Catterall WA (1993) Convergent regulation of sodium channels by protein kinase $\mathrm{C}$ and cAMP-dependent protein kinase. Science 261:1439-1442.

Loughney K, Kreber R, Ganetzky B (1989) Molecular analysis of the para locus, a sodium channel gene in Drosophila. Cell 58:11431154.

Mandel G (1993) Sodium channel regulation in the nervous system: how the action potential keeps in shape. Curr Opin Neurobiol 3:278282.

Numann R, Catterall WA, Scheuer T (1991) Functional modulation of brain sodium channels by protein kinase $\mathrm{C}$ phosphorylation. Science 254:115-118.

O'Dowd DK (1995) Voltage-gated currents and firing properties of embryonic Drosophila neurons in a chemically defined medium. J Neurobiol, in press.

O'Dowd DK, Aldrich RW (1988) Voltage-clamp analysis of sodium channels in wildtype and mutant Drosophila neurons. J Neurosci 8:3633-3643.

O'Dowd DK, Germerada S, Aldrich RW (1989) Alterations in the expression and gating of Drosophila sodium channels by mutations in the para gene. Neuron 2:1301-1311.

Qu Y, Rogers J, Tanada T, Scheuer T, Catterall WA (1994) Modulation of cardiac $\mathrm{Na}^{+}$channels expressed in a mammalian cell line and in ventricular myocytes by protein kinase C. Proc Natl Acad Sci USA 91:3289-3293.

Saito M, Wu C-F (1991) Expression of ion channels and mutational effects in giant Drosophila neurons differentiated from cell divisionarrested embryonic neuroblasts. J Neurosci 11:2135-2150.

Sambrook JM, Fritsch EF, Maniatis T (1989) Molecular cloning: a laboratory manual. Cold Spring Harbor, NY: Cold Spring Harbor Laboratory.

Sarao R, Gupta SK, Auld VJ, Dunn RJ (1991) Developmentally regulated alternative RNA splicing of rat brain sodium channel mRNAs. Nucleic Acids Res 19:5673-5679.

Schaller KL, Krzemien DM, McKenna NM, Caldwell JH (1992) Alternatively spliced sodium channel transcripts in brain and muscle. J Neurosci 12:1370-1381.

Smith M, O'Dowd D (1994) Cell-specific regulation of agrin RNA splicing in the chick ciliary ganglion. Neuron 12:795-804.

Smith RD, Goldin AL (1992) Protein kinase-A phosphorylation en- 
hances sodium channel currents in Xenopus oocytes. Am J Physiol 263:C660-C666.

Thackeray JR, Ganetzky B (1994) Developmentally regulated alternative splicing generates a complex array of Drosophila para sodium channel isoforms. J Neurosci 14:2569-2578.

Timpe LC, Jan YN, Jan LY (1988a) Four CDNA clones from the Shaker locus of Drosophila induce kinetically distinct A-type potassium currents in Xenopus oocytes. Neuron 1:659-667.

Timpe LC, Schwarz TL, Tempel BL, Papazian DM, Jan YN, Jan LY (1988b) Expression of functional potassium channels from Shaker cDNA in Xenopus oocytes. Nature 331:143-145.

Trimmer JS, Cooperman SS, Tomiko SA, Zhou J, Crean SM, Boyle MB, Kallen RG, Sheng Z, Barchi RL, Sigworth FJ, Goodman RH, Agnew WS, Mandel G (1989) Primary structure and functional expression of a mammalian skeletal muscle sodium channel. Neuron 3:33-49.

Weiss RE, Horn R (1986) Functional differences between two classes of sodium channels in developing rat skeletal muscle. Science 233: 361-364.

West JW, Numann R, Murphy BJ, Scheuer T, Catterall WA (1991) A phosphorylation site in the $\mathrm{Na}^{+}$channel required for modulation by protein kinase C. Science 254:866-868.

Westenbroek RE, Merrick DK, Catterall WA (1989) Differential subcellular localization of the $\mathrm{R} 1$ and $\mathrm{R} I \mathrm{I} \mathrm{Na}^{+}$channel subtypes in central neurons. Neuron 3:695-704.

White MM, Chen L, Kleinfield R, Kallen RG, Barchi RL (1991) SkM2, a $\mathrm{Na}^{+}$channel cDNA clone from denervated skeletal muscle, encodes a tetrodotoxin-insensitive $\mathrm{Na}^{+}$channel. Mol Pharmacol 39:604 608.

Yarowsky PJ, Krueger BK, Olson CE, Clevinger EC, Koos RD (1991) Brain and heart sodium channel subtype mRNA expression in rat cerehral cortex Pror Natl Acad Sci USA 88:9453-9457.

Zagotta WN, Hoshi T, Aldrich RW (1989) Gating of single Shaker $\mathrm{K}^{+}$ channels in Drosophila muscle and in Xenopus oocytes injected with Shaker mRNA. Proc Natl Acad Sci USA 36:7243-7247. 